\title{
MODEL LAB SITE PLS MELALUI PELEMBAGAAN RUMAH PINTAR BU EEN
}

\author{
${ }^{1}$ Oong Komar, ${ }^{2)}$ Dadang Yunus \\ ${ }^{1)}$ Program Studi Pendidikan Luar Sekolah Fakultas Ilmu Pendidikan \\ Universitas Pendidikan Indonesia \\ email: prof.oongkomar@upi.edu \\ ${ }^{2)}$ Program Studi Pendidikan Luar Sekolah Fakultas Ilmu Pendidikan \\ Universitas Pendidikan Indonesia \\ email: dadangyunus@upi.edu
}

\begin{abstract}
This study was based-backs SCTV findings regarding the phenomenal figure of Mrs. Een Sukaesih as inspirational women in the learning of the children and the community built around that by SCTV was awarded the Special Awards category of education, dedication to the community and humanity. With the assistance of assistance by the department (laboratory) facilities design by PLS embodies the children's learning and community development are packed with smart home albarokah name, and has five program activity centers. The formulation of the research problem: (1) whether the exploration results in Rumpin Albarokah there is a vision, mission, goals, objectives and programs and their conformity with the realization? (2) whether the results of the analysis are Rumpin Albarokah delegation, leadership and familiarization program implementation strategy? (3) How do find / labsite PLS models prove effective in enhancing the competence of students on community empowerment through Andragogy approach? Qualitative research approach with data collection techniques interview, observation and document and using processing techniques and data analysis with data reduction, data display and verification. This study places in Rumpin Albarokah Sumedang, West Java. The results show Rumpin are: (1) tools for community empowerment that embodies the activity of children, youth, and elderly women, (2) facilitate learning and empowerment, (3) prove the model lab site PLS is effective in enhancing the competence of students on community empowerment through approach Andragogy,
\end{abstract}

Keywords: lab site PLS, smart home, the center of activities, institutionalization, pedagogy.

\section{A. PENDAHULUAN}

Jurusan pendidikan luar sekolah Fakultas ilmu pendidikan Universitas pendidikan indonesia (PLS-FIP-UPI) memiliki empat konsentrasi kajian, yaitu: pendidikan anak usia dini (early childhood education), pendidikan dasar dan berkelanjutan (basic and continuing education), pemberdayaan masyarakat (community empowerment), serta pelatihan dan pengembangan sumber daya manusia (training and human resources development). Konsentrasi kajian pemberdayaan masyarakat merupakan bagian substantif terkait dengan dimensi keahlian/kajian pendekatan multidimensional melalui pengembangan Laboratorium PLS. Lab site PLS, merupakan tempat uji petik penyiapan calon-calon tenaga profesional yang kreatif, beretos kerja tinggi dan berkompetensi menangani bentuk penyelenggaraan program PNFI yang sesuai dengan perkembangan tuntutan kebutuhan belajar masyarakat. Sehingga untuk sarana pengembangan akademis mahasiswa di perguruan tinggi perlu memikirkan dan melaksanakan "program $a k s i$ " sebagai perwujudan penguasaan praktisnya melalui lab site. 
PEDAGOGIA : Jurnal IImu Pendidikan

Lab site Rumah Pintar merupakan pusat pemberdayaan masyarakat guna meningkatkan taraf hidup menuju masyarakat sejahtera. Rumah Pintar sebagai sarana pemberdayaan masyarakat yang mewadahi berbagai kegiatan mulai dari pendidikan anak usia dini, remaja, kaum perempuan sampai dengan kelompok lanjut usia. Diharapkan melalui Rumah Pintar dapat membangun masyarakat cerdas, inovatif, kreatif, mandiri dan sejahtera.

Rumah pintar dipelopori Solidaritas istri Kabinet Indonesia Bersatu (SIKIB). Dalam situsnya mengungkapkan (www.rumahpintar.go.id/26 Februari 2014) bahwa rumah pintar muncul dari ide/pemikiran Ibu Negara untuk turut berperan dalam mensejahterakan bangsa. Ibu Negara bersama Solidaritas Isteri Kabinet Indonesia Bersatu (SIKIB) menggagas Program Indonesia Pintar. Tujuan utama dari Program Indonesia Pintar adalah mewujudkan masyarakat berpengetahuan, masyarakat sejahtera (welfare society) dan masyarakat yang beradab (civilized society).

Namun, persepsi mahasiswa mengenai penguasaan kompetensi masih sebatas pemilikan pengetahuan yang dipelajari, apalagi sampai pada penguasaan praktis dari ilmu yang dipelajarinya. Rintisan pelembagaan rumah pintar yang ada pun cenderung bersifat formalitas dan tingkat keberlanjutan program yang rendah.

Oleh karena itu, rintisan penyelenggaraan program lab site Pendidikan Luar Sekolah melalui pelembagaan rumah pintar diharapkan menjadi media implementasi keilmuan teoritis atau penerapan konsep-teoritik yang telah diperoleh mahasiswa di perkuliahan guna peningkatan kompetensi profesional lulusan.

Melalui rintisan model pelembagaan

rumah pintar dengan pendekatan

andragogis untuk upaya peningkatan kompetensi lulusan prodi PLS yang harus

dimiliki mahasiswa dalam

penyelenggaraan dan pengelolaan

program pendidikan non formal adalah

andragogis. Darkenwald dan Merriam

(1982:9) mengungkapkan andragogi ialah

suatu proses belajar yang sistematis dan

berkelanjutan pada seseorang yang

memiliki status dewasa (berdasarkan ciri

utama peran sosialnya) dengan tujuan

untuk mencapai perubahan pada

pengetahuan, sikap, nilai dan

keterampilannya.

Berdasarkan latar belakang dan identifikasi masalah yang diuraikan di atas, maka permasalahan pokok adalah bagaimana model pelembagaan rumah pintar melalui pendekatan andragogis dalam upaya peningkatan kompetensi mahasiswa Jurusan Pendidikan Luar Sekolah (PLS)? Rumusan masalah penelitian: (1) apakah hasil eksplorasi di rumah pintar (rumpin) Albarokah terdapat visi, misi, tujuan, sasaran dan program serta adanya kesesuaian dengan realisasinya? (2) apakah hasil analisis di rumpin Albarokah terdapat pendelegasian, kepemimpinan dan pembudayaan strategi pengimplementasian program? bagaimanakah menemukan/membuktikan model labsite PLS yang efektif dalam peningkatan kompetensi mahasiswa mengenai pemberdayaan masyarakat melalui pendekatan andragogi?

Tujuan penelitian untuk menemukan model labsite PLS yang efektif dalam peningkatan kompetensi mahasiswa mengenai pemberdayaan masyarakat melalui pendekatan andragogi.

\section{B. STUDI LITERATUR}

Secara teoretis suatu lembaga adalah wadah, wahana dan proses penyelenggara berbagai kegiatan untuk mencapai tujuan. Tugas pimpinan atau 
melalui kepemimpinannya berusaha melembagakan budaya (cultural make up) dengan menggerakkan implementasi strategi berbagai kegiatannya untuk mencapai tujuan tersebut. Dengan kepemimpinan, maka kondisi setiap satuan kerja dapat memancarkan etos kerja dan sistem nilai kebersamaan. Setiap pekerja akan menampilkan perilaku yang menggambarkan etos kerja dan sistem nilai, bahkan kepribadian yang dianut lembaga.

Menurut Sondang P. Siagian (2008), esensi budaya lembaga berfungsi: (1) menyadari batas perilaku yang boleh atau tidak boleh dilakukan, (2) merasa memiliki dengan sedia berkomitmen kelembagaan, (3) merasa bangga menjadi anggota lembaga dan berkarya pada lembaga tersebut, (4) memelihara stabilitas dan pengikat kebersamaan, (5) bagi pimpinan dapat dijadikan alat pengendalian perilaku para anggotanya.

Dari sudut pandang teore konektivitas antara strategi implementasi kebijakan dengan penciptaan budaya, mesti terlihat budayanya itu memberi arah tentang (1) perilaku yang ditampilkan, (2) tugas yang dikejakan, dan (3) skala prioritas yang ditetapkan. Budaya tersebut menggambarkan jembatan antara ketentuan/ aturan dengan kenyataan melalui kepribadian kepemimpinan. Meskipun budaya suatu lembaga tidak mudah dilihat dengan kasat mata, sebab bersifat implisit, tapi setiap lembaga harus menciptkan iklim budaya (cultural make up) tertentu, seperti komitmen, norma dan etos kerja yang dapat mengatur perilaku anggotanya sehari-hari. Sehingga bagi lembaga UPI, kiranya butuh waktu yang cukup untuk melakukan upaya penelusuran budayanya, apalagi hingga menentukan ciri khas budayanya. Saat ini kiranya lebih tepat menggagas usaha membangun budaya UPI.
Budaya lembaga dibangun dengan tiga faktor (Sondang P. Siagian, 2008), yaitu menciptakan struktur lembaga, menciptakan kepemimpinan dan menumbuh-kembangkan budaya. Menciptakan struktur lembaga sama halnya dengan membagi habis kewenangan lembaga. Artinya siapa yang melakukan kegiatan apa. Siapa yang bertanggujawab kepada siapa. Siapa yang berinteraksi dengan siapa. Pola komunikasi bagaimana yang berlaku dan jaringan informasi apa yang tersedia. Kejelasan struktur organisasi atau pembagian kerja memerlukan kepemimpinan. Manajer puncak (top manager) sangat menentukan kepemimpinannya. Manajer puncak menjadi katalisator utama dalam peran simbolik dan substantif. Manajer puncak dengan kesungguhan harus mendorong tumbuhnya kegiatan kerja dan komitmen pengimplementasian strategi program lembaga, sehingga misi, strategi dan sasaran lembaga dipengaruhi kepribadian, nilai dan etos kerja yang diciptakan manajer puncak.

Persepsi bawahan terhadap manajer puncak harus menggambarkan suatu asumsi, kesepakatan, norma yang mengatur perilaku anggota. Makna kehidupan bersama tercermin dalam perilaku anggota. Setiap anggota menampilkan perilaku yang menggambarkan sistem nilai, keyakinan, etos kerja yang dianut lembaga. Anggota mempunyai ciri kondisi, kepribadian, sistem nilai, keyakinan, etos kerja dan komitmen yang sifatnya khas, sebagaimana rancangan yang diciptakan manajer puncak, sehingga budaya tersebut menjadi khas yang dapat membedakan antara lembaganya dengan lembaga lain.

Penguasaan kompetensi yang masih sebatas pemilikan pengetahuan yang dipelajari, apalagi sampai pada penguasaan praktis dari ilmu yang dipelajarinya. Bahkan melalui rintisan pelembagaan 
rumah pintar yang ada pun cenderung bersifat formalitas dan tingkat kelanjutan programnya yang rendah. Oleh karena itu, rintisan penyelenggaraan program lab site Pendidikan Luar Sekolah melalui pelembagaan rumah pintar diharapkan menjadi media implementasi keilmuan teoritis atau penerapan konsep-teoritik yang telah diperoleh mahasiswa di perkuliahan guna peningkatan kompetensi lulusan yang profesional.

Profesional adalah melakukan layanan yang baik terhadap kliennya. Layanan yang baik ditopang disiplin ilmu yang kokoh. Sehingga profesi PLS harus melakukan layanan yang baik dan ditopang disiplin ilmu yang kokoh. PLS berfungsi melayani kebutuhan pendidikan di luar sistem sekolah, sehingga kehdirannya sebagai bidang layanan khusus. Yaitu untuk (1) meningkatkan kualitas hidup bagi masyarakat tertinggal (pengentasan), dan (2) membebaskan masyarakat yang tertindas (pemberdayaan).

Oleh karena itu, tenaga PLS dalam memberikan layanan profesionalnya harus: (1) merasa pangilan jiwa dalam melayani kliennya, (2) dibekali disiplin ilmu yang kokoh dalam menunaikan tugasnya, dan (3) memiliki kode etik PLS guna melindungi otonomi profesinya.

Dua asumsi pemikiran PLS. Pertama, masyarakat yang tertinggal disebabkan kelemahan sendiri. Kedua, masyarakat yang terlantar disebabkan struktur sosial yang hegemoni.

$\begin{array}{ccc}\begin{array}{c}\text { Fungsi } \\ \text { layanan } \\ \text { tertinggal }\end{array} & \text { PLS } \begin{array}{r}\text { bagi } \\ \text { adalah }\end{array}\end{array}$
meningkatkan kualitas SDM menuju tarap hidup yang lebih baik. Sementara fungsi layanan PLS bagi masyarakat tertindas adalah melakukan pemberdayaan dan pembebasan menuju terciptanya transformasi sosial yang bebas dari struktur sosial yang hegemoni.
Andragogi termasuk disiplin ilmu PLS yang menopang upaya peningkatan masyarakat tertinggal. Prinsip-prinsip Andragogi: (1) menganggap manusia bersifat dewasa, (2) manusia memiliki kekayaan pengalaman, (3) siap belajar yang praktis. Sementra Pedagogik Kritis termasuk disiplin ilmu PLS yang menopang upaya pembebasan terlantar/tertindas. Prinsip-prinsip Pedagogik kritis: (1) penyadaran diri melalui refleksi, aksi, kreasi dan kritisi (evaluatif/assessment), (2) transformatif emensipatoris.

Selain itu, disiplin ilmu PLS memiliki sifat akademik dan profesional. Yang bersifat akademik adalah bidang kajian dengan obyek disiplin ilmu layanan PLS pada aktivitas yang melembaga. Sementara yang bersifat profesional adalah bidang layanan dengan obyek operasional kelembagaan dan gerakan praktisi PLS.

\section{METODE PENELITIAN}

Penelitian ini mengunakan metode kualitatif, yaitu penelitian yang berlandaskan pada filsafat postpositivisme untuk meneliti kondisi obyek yang alamiah. Lokasi penelitian dilaksanakan di Rumah Pintar Al Barokah Bu Een yang berlokasi di Dusun Batu Karut Desa Cibereum Wetan Kecamatan Cimalaka Kabupaten Sumedang. Waktu penelitian bulan Mei sd September 2014. Subjek penelitian atau responden dalam penelitian ini adalah penyelenggara Rumah Pintar Al Barokah. Subjek yang diteliti adalah pengurus yang masih aktif dan terlibat dalam merintis mendirikan Rumah Pintar Al Barokah, penyelenggara, tutor, nara sumber, tokoh masyarakat dan pendamping.

Instrumen atau alat penelitian menggunakan: (1) Wawancara untuk mengetahui hal-hal dari responden yang lebih mendalam. (2) Observasi digunakan berkenaan dengan penelitian perilaku manusia, proses kerja, gejala-gejala alam 
dan bila responden yang diamati tidak terlalu besar. (3) Studi Dokumentasi untuk mengetahui catatan peristiwa yang sudah berlalu dalam bentuk tulisan, gambar, atau karya-karya monumental dari seseorang.

Validasi data agar kredibel atau untuk meningkatkan derajat kepercayaan data melalui triangulasi, yakni pengecekan, pemeriksaan dari data yang telah diperoleh di lapangan terutama untuk memperoleh keabsahan data. Pada tahap ini dilakukan kegiatan membandingkan hasil observasi dengan hasil wawancara dan membandingkan hasil wawancara warga belajar (lulusan) dengan orang lain. Hal ini, sejalan dengan pendapat Patton (Ali Budiyana, 2002:50) menjelaskan kegunaan triangulasi adalah untuk membandingkan data hasil pengamatan dengan hasil wawancara, apa yang dikatakan orang didepan umum dengan apa yang dikatakan orang secara pribadi, hasil wawancara dengan dokumen yang berkaitan.

Selain triangulasi, dilakukan pula: (1) perpanjangan masa pengamatan memungkinkan peningkatan derajat kepercayaan data yang dikumpulkan, bisa mempelajari kebudayaan dan dapat menguji informasi dari responden, dan untuk membangun kepercayaan para responden terhadap peneliti dan juga kepercayaan diri peneliti sendiri. (2) pengamatan yang terus menerus, untuk menemukan ciri-ciri dan unsur-unsur dalam situasi yang sangat relevan dengan persoalan atau isu yang sedang diteliti, serta memusatkan diri pada hal-hal tersebut secara rinci. (3) Peer debriefing (membicarakannya dengan orang lain) yaitu mengekspos hasil sementara atau hasil akhir yang diperoleh dalam bentuk diskusi analitik dengan rekan-rekan sejawat.
Sementara analisis data untuk proses mencari dan menyusun secara sistematis data yang diperoleh dari hasil wawancara, catatan lapangan, dan bahanbahan lain,sehingga dapat mudah dipahami, dan temuannya dapat diinformasikan kepada orang lain dengan menempuh langkah-langkah mensortir, memilah dan menyusun secara sistematis data-data yang diperoleh dari hasil wawancara, observasi/catatan lapangan dan dokumentasi, agar data tersebut terorganisasi secara kategoris, terjabar ke dalam unit-unit, melakukan sintesa, menyusun ke dalam pola, memilih mana yang penting dan membuat kesimpulan sehingga mudah dipahami.

Langkah menganalisis data tersebut meliputi: (1) Data Reduction (Reduksi Data) berarti merangkum, memilih hal-hal yang pokok, memfokuskan pada hal-halyang penting, dicari tema dan polanya. Data yang telah direduksi akan memberikan gambaran yang lebih jelas, dan mempermudah peneliti untuk melakukan pengumpulan data selanjutnya dan mencarinya bila diperlukan. (2) Data Display (Penyajian Data) yaitu penyajian data dalam bentuk tabel, grafik, phie chard, pictogram dan sejenisnya, seperti uraian singkat secara naratif, bagan, hubungan antar katageri dan flowchart. (3) Verification adalah penarikan kesimpulan, yaitu menyajikan data yang mendukung dengan sifat bukti valid, konsisten dan kredibel. Sehingga kesimpulan penelitian merupakan temuan baru berupa deskripsi atau gambaran suatu obyek dengan eksplanasi/jelas, hubungan kausal atau interaktif, dan jawaban hipotesis atau kaitan pada teori.

Alur penelitian sebagaimana uraian di atas, digambarkan sebagai berikut 


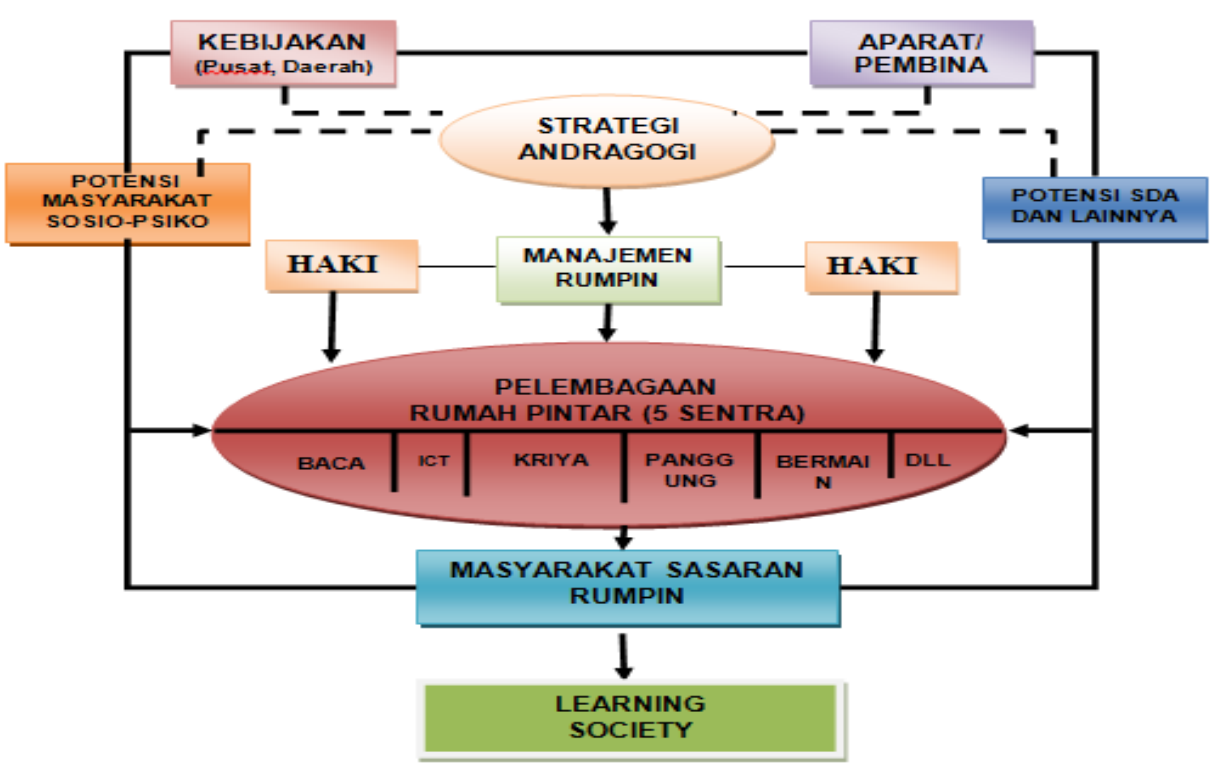

Gambar: 1. Alur Penelitian

\section{HASIL DAN PEMBAHASAN}

Rumah Pintar (rumpin) AlBarokah, beralamat di Jl. Raya SumedangCirebon, Dusun Batu Karut, Desa Cibeureum Wetan, Kecamatan Cimalaka, Kabupaten Sumedang. Rumpin berawal dari tempat privat/less siswa yang diberikan oleh Ibu Een Sukaesih, figur/sosok Ibu Een Sukaenah menunjukkan peran sebagai agen pembaharu atau tokoh masyarakat yang berusaha memenuhi kebutuhan belajar masyarakat sekitarnya. Rumpin ditingkatkan menjadi jenis satuan pendidikan non formal guna meningkatkan pemberian layanannya pada warga masyarakat yang membutuhkannya, dengan difasilitasi oleh kerjasama antara Yayasan Swandragogia, Lab-site Jurusan Pendidikan Luar Sekolah Fakultas Ilmu Pendidikan Universitas Pendidikan Indonesia dan Direktorat Pembinaan Pendidikan Masyarakat DITJEN PAUDNI KEMDIKBUD.

Rumpin menunjukkan peningkatan, dengan indikasi: Partisipasi warga belajar yang intensif dalam mengikuti berbagai macam event atau program Rumah Pintar,
Partisipasi dan daya dukung dari pengelola/pengurus serta tokoh masyarakat yang bersedia dan ikut terlibat dalam kepengurusan Rumah Pintar Al Barokah, Potensi sumber daya alam yang khas yakni buah naga dan hasil panen kolam ikan menjadi stimulan pengelola untuk kreatif mengolah, mengemas dan memasarkan produk tersebut ke pasaran sehingga menghasilkan pendapatan untuk rumpin dan masyarakat sekitar, Daya dukung pemerintah dalam memberikan kemudahan aksesibilitas mengurus hal-hal yang sifatnya administratif untuk pelembagaan Rumah Pintar, Sarana dan prasarana baik sarana fisik (gedung yang sedang tahap finalisasi pembangunanya) dan sarana pembelajaran yang dimilikinya cukup lengkap, memadai dan layak untuk digunakan, Jejaring kemitraan yang luas dengan berbagai mitra seperti ; instansi pemerintah (Desa, Camat, Dinas Pendidikan, Kemdikbud dan sebagainya), Perguruan Tinggi (baik negeri maupun swasta), SEAMOLEC, BUMN dan organisasi masyarakat lainnya.

Rumpin merupakan model labsite PLS dengan pendekatan Andragogi terbukti efektif dalam meningkatkan 
kompetensi mahasiswanya mengenai pemberdayaan masyarakat, dengan pengorganisasian rumpin disegala bidang, terutama pengorganisasian program yang dilaksanan dengan menggunakan pengorganisasian/pembidangan sentra program kegiatan, yaitu: Sentra Buku, Sentra Bermain, Sentra Panggung, Sentra Komputer dan Sentra Kriya.

Kondisi pendidikan nonformal seolah merupakan kompleksitas suatu spektrum. Pendidikan nonformal sangat dibutuhkan masyarakat, tetapi ternyata optimalisasinya masih jauh dari harapan. Telah dirasakan sejak memasuki abad ke21 posisi PNF sangat strategis dengan tuntutan sistem pendidikan dan pelatihan di industri untuk meningkatkan kualitas sumber daya manusianya, sehingga perlu paradigma baru keilmuan PNF. Paradigma baru PNF sangat terasa kebutuhan untuk pengembangan sistem pendidikan dan pelatihan di industri untuk meningkatkan kualitas sdm, karena pengetahuan, keterampilan, nilai, sikap dan penyesuaian memiliki peran penting dalam menghadapi ekonomi baru dan tantangannya. Tempat kerja (industri), sangat memperhatikan kebutuhan pengembangan kualitas sdm agar dapat mendukung kemajuan ekonomi, persaingan dan kemakmuran. Manusia dipandang sebagai faktor utama bagi aktifitas ekonomi, persaingan, dan kemakmuran. Tamatan sekolah yang sudah bekerja dituntut meningkatkan pengetahuan dan keterampilan agar tidak tertinggal dari perkembangan iptek.

Kiprah pendidikan nonformal secara nasional meliputi kelembagaan, program aksi dan ketenagaan. Pertama, kelembagaan pendidikan nonformal meliputi: PAUD (kelompok bermain, TPA, TK/RA dan yang sejenis), PKBM, Kursus, TBM, Forum satuan pendidikan nonformal (Majelis Taklim, Organisasi Perempuan, HIPKI, HISPPI, Asosiasi Propesi Kursus, Forum PAUD, Forum
PKBM, dan sebaginya), UPT P2PNFI dan BPPNFI, UPTD BPKB dan SKB.

Kedua, program aksi pendidikan nonformal meliputi: PAUD, keaksaraan fungsional, Paket A, B, dan C, kursus, $\mathrm{KBU}$, magang, peningkatan budaya baca dan perpustakaan, pengarusutamaan jender, program pendidikan nonformal sejenis seperti life skills, beasiswa, belajar jarak jauh dan pendidikan maya.

Ketiga, ketenagaan pendidikan nonformal terdiri atas pendidik dan tenaga kependidikan. Pertama, pendidik pendidikan nonformal dan informal meliputi: (1) pamong belajar UPT P2PNFI dan BPPNFI, UPTD BPKB/SKB, (2) fasilitator desa intensif (FDI), (3) tutor KF, (4) tutor Paket A, B, C, (5) pendidik dan pengasuh PAUD, (6) pendidik dan penguji praktek kursus, (7) nara-sumber teknis KBU, (8) pendidik pendidikan nonformal sejenis, seperti instruktur diklat, magang, widyaiswara dan penyuluh. Kedua, tenaga kependidikan pendidikan nonformal meliputi: (1) penilik, (2) tenaga lapangan dikmas (TLD), (3) pengelola PKBM, (4) pengelola kelompok belajar, (5) pengelola kursus, (6) pengelola TBM, (7) pengelola PAUD dan (8) tenaga kependidikan satuan pendidikan nonformal lainnya (pengelola $\mathrm{KBU} /$ magang, laboran, pustakawan, dan sebagaunya).

Ivan Illich (1974) memandang pendidikan nonformal sebagai alternative to schooling. Sehingga masyarakat harus membuang anggapan bahwa hanya sekolah yang mampu memberi bekal bermutu. Padahal pendidikan nonformal terbukti dalam banyak hal menjadi pendidikan alernatif atau penyelamat.

Pendidikan nonformal dibebani tugas melaksanakan komitmen dunia melalui program aksi pendidikan untuk semua (EFA) dan tujuan pembangunan millennium (MDGs). Target EFA terdiri atas: pendidikan usia dini, pendidikan dasar formal, life skill, keaksaraan, 
kesetaraan jender dalam pendidikan dan peningkatan mutu pendidikan. Adapun target MDGs terdiri atas (a) penghapusan kemiskinan dan kelaparan ekstrem, (b) pendidika dasar untuk semua, (c) promosi kesetaraan jender dan pemberdayaan perempuan, (d) penurunan angka (jumlah) kematian anak, (e) perbaikan kesehatan ibu hamil, (f) penghentian penyebaran HIV/AID, malaria dan penyakit lainnya, (g) pembangunan berwawasan lingkungan yang berkelanjutan, dan (h) kemitraan global dalam perdagangan dan sistem keuangan.

Target nasional program pendidikan nonformal meliputi: (a) pendidikan kesetaraan untuk mendukung kesuksesan wajib belajar pendidikan dasar 9 tahun, (b) pendidikan keaksaraan fungsional untuk kesuksesan penurunan jumlah penduduk buta aksara usia 15 tahun ke atas, (c) PAUD untuk persiapan anak masuk sekolah, (d) kursus dan pelatihan untuk pemenuhan kebutuhan belajar masyarakat, (e) life skill untuk membekali warga belajar hidup mandiri, (f) pemberdayaan perempuan untuk pengarusutamaan jender bidang pendidikan, (g) budaya baca masyarakat untuk peningkatan kualitas pendidikan masyarakat, dan (h) pengembangan kelembagaan pendidikan nonformal untuk menunjang keberhasilan programnya.

Oleh karena itu, pendidikan nonformal "hidup" dan dibutuhkan masyarakat. Di antaranya untuk pemberdayaan diri, peningkatan keterampilan kerja, penyesuaian diri dan lingkungan. Bahkan kebutuhan inservice training pekerja untuk memenuhi tuntutan profesionalitas dan layanan prima. Pilihan pendidikan nonformal oleh sejumlah masyarakat disebabkan pembelajarannya bersifat instant dan dapat ditempuh sambil bekerja. Selain itu, pendidikan nonformal dijadikan sebagai (1) wahana pendidikan alternatif, (2) cara belajar untuk maju, mandiri, wirausaha dan kerja kreatif, (3) mengembangkan watak lepas dari ketergantungan dan mencitptakan lapangan kerja, (4) magang dan (5) penciptaan iklim masyarakat belajar (learning society).

Berdasarkan kajian di atas, kirnya perlu reposisi orientasi UPT/SKB menjadi modeling pendidikan nonformal sebagai alternative to schooling. Pendidikan nonformal terbukti dalam banyak hal menjadi pendidikan alernatif atau penyelamat.

\section{E. SIMPULAN DAN REKOMENDASI}

\section{Simpulan}

Hasil analisis/verifikasi kualitatif menunjukkan bahwa rumpin adalah: (1) sarana pemberdayaan masyarakat yang mewadahi kegitan anak, remaja dan wanita lanjut usia, (2) fasilitas pembelajaran dan pemberdayaan masyarakat, (3) model labsite PLS dengan pendekatan Andragogi terbukti efektif dalam meningkatkan kompetensi mahasiswanya mengenai pemberdayaan masyarakat.

\section{Rekomendasi}

Rekoendasi yang mungkin dirumuskan adalah: (1) meningkatkan penguatan kapasitas pengelola Rumah Pintar melalui diklat penataan dan pengelolaan program serta tatalaksana keadministrasian, (2) meningkatkan kompetensi tutor melalui diklat pemahaman manajemen program pendidikan non formal, (3) penyempurnaan pendekatan andragogi dalam model pelembagaan lab-site PLS, sebagai upaya peningkatan kompetensi mahasiswanya mengenai pemberdayaan masyarakat.

\section{F. REFERENSI}

Sardiman,A.M. (2001). Interaksi dan Motivasi Belajar Mengajar. 
Jakarta: PT. Raja Grafindo

Persada

Abdulhak, I. (2000). Metodologi Pembelajaran Orang Dewasa. Bandung: Andira.

Anisah dan Syamsu (2011:13). Psikologi Perkembangan Anak dan Remaja. Bandung : PT Rosdakarya

Arif, Zainudin. (1993). Andragogi.

Bandung : Angkasa

Arikunto, S. (2010). Prosedur Penelitian Suatu Pendekatan Praktik. Jakarta : Rineka Cipta.

Desmita. (2012). Psikologi

Perkembangan. Bandung: PT. Remaja Rosdakarya

Hanafi, Abdilah (1981). Memasyarakatkan Ide-Ide Baru. Surabaya : Usaha Nasional

Knowless, S Malcolm (1977). The Modern Practice of Adult Education. New York ; Association Press

Marzuki,Saleh. (2010. Pendidikan Nonformal: Dimensi dalam Keaksaraan Fungsional,Pelatihan dan Andragogi. Bandung: PT. Remaja Rosdakarya

Nazir. (2005). Metode Penelitian. Bogor:

Ghalia Indonesia

Rahmat, Abdul (2008). Andragogi Ilmu dan Seni Belajar Orang Dewasa. Sukabumi ; Patlot Cendikia Press
Santoso,Selamet. (2010). Teori-teori Psikologi Sosial. Bandung : PT.Refika Aditama

Suciati.(2012). Strategi Proses Pembelajaran Pada Kursus Menjahit Tingkat Dasar di Lembaga Kursus dan Pelatihan Pelita Massa Bandung. Bandung: UPI Tidak diterbitkan

Sudjana, Djudju. (2001). Pendidikan Nonformal, Wawasan, Sejarah Perkembangan, Falsafah, Teori Pendukung, Azas. Bandung : Falah Production.

Sugiyono. (2011). Metode Penelitian Pendidikan Pendekatan Kuantitatif, Kualitatif dan $R \& D$. Bandung : Alfabeta.

Sugiyono. (2012). Metode Penelitian Kombinasi (Mixed Methode). Bandung : Alfabeta.

Suprijanto, H. (2012). Pendidikn Orang Dewasa dari Teori Hingga Aplikasi. Jakarta : PT.Bumi Aksara

Sutikno (2013:31). Belajar Dan pembelajaran. Lombok : Holistica

Taqiyuddin.M. (2008). Pendidikan Untuk Semua: Dasar dan Falsafah Pendidikan Luar Sekolah. Bandung: Mulia Press

Uno, Hamzah B. (2007). Teori Motivasi dan Pengukurannya. Jakarta : Bumi Aksara. 
Universitas Pendidikan Indonesia. (2013).

Pedoman penulisan Karya Ilmiah

Universitas pendidikan Indonesia.

Bandung : UPI Press.

PP No.73 tahun 1991 tentang Pendidikan Luar Sekolah

\section{Sumber Internet :}

http:

//seputarpengertian.blogspot.com/

2014/04/pengertian-tutor.html)

Botkin, J.W., dkk (1984). No Limits To Learning: Bridging The Gaps, Oxford Pergamon Press.

Brembeck, C.S., dkk (1973) New Strategies for Educational Development, Toranto, Heath Company.

Brookfield, S. (1984). Adult Learners, Adult Education and the Community, Columbia University, New York. Teaches College Press.

Coombs, P. H. (1968) World Educational Crisis: a systems approach, New York: Oxford University Press.

Coombs, P. (1985) The World Crisis in Education, New York: Oxford University Press.

Delors, J., (1996). Learning: The Treasure Within. Paris: Unesco

DePorter, N., dkk. (1999) Quantum Learning. Membiasakan Belajar Nyaman dan Menyenangkan. Bandung. Kaifa
Elias, J.L., dkk (1980) Philosophical Foundation of Adult Education. Malabar florida. Robert E. Kreiger.

EU Memo, (2000) Memorandum on Lifelong Learning, Commission Staff Working Paper.

Freire. P., (1970). Pedagogy of the Oppressed. New York: the Searbury Press.

Harbison, S.S (1982) Pengertian, Falsafah dan Azas Pendidikan Non Formal (suatu pendapat) : Bandung

Inggalls, J. (1973). A Trainer Guide To Andragogy It is Concept, Experience and Application, Washington Departemen of Health Education and Welfare.

Inkeles, A., dkk (1982) Handbook in Research and Evaluation: For Education and Behavioral Science. San Diego California. Edits.

Jarvis, P. (1983). Adult and Continuing Education: Theory and Practice. London Croom Helm.

Kamil, Mustofa, (2001), Model Pembelajaran Magang Bagi Peningkatan Kemandirian, Bandung, PPS, UPI.

Kinderverter, S., (1979) Non Formal Education as an Empowering Process. Amherst, Massachusett. University of Massachusett.

Knowles, M., (1950). Informal Adult Education: A Guide For Administrator, Leader and Teachers. New York. Association Press. 
Krech, R., (1989) The Enterpreneur Handbook: Manila University. UPISSI of The Philippine, Institute of Small Scale Industry.

Lindeman, E. C. (1926) The Meaning of Adult Education (1989 edn.), Norman: University of Oklahoma.

Maslow, H.A., (1977) The Further Reaches of Human Nature, New York: the Viking Press.

Rogers, A. (1994). Teaching Adults. Open University Press, Milton Keynote.

Srinivasan, L (1977). Perspectives on Non Formal Adult Learning: Functional Education For Individual, Community and National Development, Connecticut Prentice Hall.

Sudjana, D. (2000), Pendidikan Luar Sekolah, Sejarah, Azas, Bandung Falah Production

Toffler, A (1970). The Future shock. New York. Random House.

UNESCO (1972) Learning to Be (prepared by Faure, E. et al), Paris: UNESCO.

UNESCO, (1993), Continuing education: New policies and Directions, UNESCO Principal Regional Office for Asia and the Pacific, Bangkok.

UNICEF, UNESCO, (2006), Identifying and reaching the unreached, Education for all Asia and the Pacific.
Basu Swasta (...), Azas Manajemen Modern, BPFE:, Yogyakarta

COMEM, (2008).Policy Paper on Non-Formal Education:A framework for indicating and assuring quality, Adopted by the Council of Members/ Extraordinary General Assembly 2-3 May 2008 (Castelldefels, Catalonia - Spain)

George R Terry, (2000)Prinsip-prinsip Management, Bumi Aksara: Jakarta,

Hani Handoko (...), Manajemen, BPFE, Yogyakarta.

James AF Stoner, (1992). Manajemen, Erlangga : Jakarta,

Ricky W Griffin, (2002)., Management (Texas A \& M University), Erlangga: Jakarta,

Merriam, Sharan B. Dan Cunningham, Phyllis M, (1989). Handbook of Adult and Continuing Education. Josey Bas:San Francisco.

Winardi, (2000). Kepemimpinan dalam Management, Rineka Cipta,

Suryono, Y,B. Manajemen Pembelajaran $P L S$, BPPNFI Bandung.

eprints.undip.ac.id/9664/1/MANAJEMEN

Bramley, Peter. (1991). Evaluating Training Effectiveness. Mc GraawHill:London

daytimeconfidential.zap2it.co

ebook-pdf.org/.../twelve-principles-foreffecti

en.wikipedia.org/.../The_Seven_Habits_of _Hi 
en.wikipedia.org/wiki/Reg_Revans

Peters John M. At all.(1980). Building an Effective Adult Education Enterprise. Jossey-Bass Pub: San Francisco.

Wentling, Tim L. (1992). Planning for Effective Training. FAO: Rome 